\title{
REFLETINDO SOBRE AS REDES SOCIAIS DIGITAIS
}

\author{
SôNia CRistina Vermelho* \\ Ana Paula Machado Velho** \\ AMANDA BONKOVOSKI*** \\ Alisson PIROLA****
}

\begin{abstract}
RESUMO: Este artigo apresenta os resultados da primeira etapa da investigação realizada pelo grupo de pesquisa Ciência, Tecnologia e Sociabilidade do Mestrado em Promoção da Saúde. Nele situamos a área da Promoção da Saúde; em seguida apresentamos uma discussão em torno do conceito de "redes sociais digitais" e, finalmente, apresentamos alguns resultados da pesquisa bibliográfica realizada nesta etapa. Os dados bibliográficos encontrados (artigos, teses e dissertações) indicaram um aumento de trabalhos publicados sobre o tema a partir de 2005 , bem como uma concentração nas áreas de Comunicação e Educação.
\end{abstract}

Palavras-chave: Redes sociais digitais. Pesquisa bibliográfica. Promoção da saúde. Jovens.

\section{REFLECTING UPON DIGITAL NETWORKS}

ABSTRACT: This article presents the results of the first stage of research conducted by the research group Science, Technology and Sociability of the Masters in Health Promotion program. First, the area of Health Promotion is situated; then a discussion around the concept of digital and social media is presented and finally some results of the literature review undertaken at this stage is discussed. The bibliographic data found (articles, theses and dissertations) indicate an increase in published papers on the topic as from

Mestrado em Promoção da Saúde do Centro de Ensino Superior de Maringá (Cesumar). Maringá (PR) - Brasil.

* Mestrado em Promoção da Saúde do Centro de Ensino Superior de Maringá (Cesumar). Maringá (PR) - Brasil.

*** Mestrado em Promoção da Saúde do Centro de Ensino Superior de Maringá (Cesumar). Maringá (PR) - Brasil.

**** Mestrado em Promoção da Saúde do Centro de Ensino Superior de Maringá (Cesumar). Maringá (PR) - Brasil.

Contato com os autores: <cristina.vermelho@gmail.com> 
2005, as well as a concentration in the areas of Communication and Education.

Key words: Social digital networks. Bibliography research. Health promotion. Teenagers.

\section{DES RÉFLÉXIONS SUR LES RÉSEAUX SOCIAUX NUMÉRIQUES}

RÉSUMÉ: Cet article présente les résultats de la première étape d'une étude menée par le groupe de recherche "Sciences, Technologie et Sociabilité", Maîtrise en Promotion de la Santé. D'abord, nous situons le secteur de la Promotion de la Santé; ensuite nous présentons une discussion autour du concept de "réseaux sociaux numériques" et, finalement, nous présentons quelques résultats de la recherche bibliographique réalisée dans cette étape. Les données bibliographiques trouvées (articles, thèses et mémoires) ont indiqué une augmentation d'articles publiés sur le sujet à partir de 2005, ainsi qu'une concentration dans les domaines de la Communication et de l'Éducation.

Mots-clés: Réseaux sociaux numériques. Recherche bibliographique. Promotion de la santé. Jeunes.

\section{Onde tudo começou}

$\mathrm{T}$

oda pesquisa começa de um ponto ou do encontro de vários pontos, os quais, pelo movimento do cotidiano, em geral, se perdem no tempo. A realização do projeto de pesquisa que deu origem a este artigo aconteceu num desses encontros que (quase) se perdeu: o de dois grupos de pesquisa que se cruzaram num determinado contexto, numa mesma instituição: um pesquisava a comunicação na era digital e outro a mídia-educação. A junção aconteceu quando os pesquisadores ingressaram no Mestrado em Promoção da Saúde, um programa interdisciplinar, com uma linha de pesquisa envolvendo as áreas de Educação e Comunicação voltadas à promoção da saúde.

No início, tudo foi muito novo, mas, aos poucos, o grupo foi encontrando sua identidade no campo da saúde. Definimos que, para subsidiar os trabalhos, seria importante buscarmos fundamentos e experiências para futuramente propormos ações e produtos de comunicação-educação com informações sobre saúde adequada para a população. Para o público jovem, indiscutivelmente, definimos que seriam as tecnologias digitais o meio mais apropriado para alcançá-lo. Com isso, estruturamos um projeto de pesquisa em duas etapas: a primeira de cunho bibliográfico e a segunda de campo. A ideia era conhecer o que vinha sendo pesquisador sobre as redes sociais digitais nos últimos dez anos (2001-2011). Este artigo traz os resultados desta primeira etapa da pesquisa.

Para iniciar a exposição, é importante conceituar o campo da Promoção da Saúde. É entendido como um campo interdisciplinar que visa instaurar processos 
de capacitação da comunidade para atuar na melhoria de sua qualidade de vida e saúde, a partir, principalmente, de uma maior participação do sujeito no processo. Tomando como base os documentos oriundos das conferências internacionais e regionais da área de Promoção da Saúde (OTTAWA, 1986; Adelaide, 1988; Sundsvall, 1991; Jakarta, 1997; México, 1999, e outras duas de caráter sub-regional em Bogotá, 1992, e Port of Spain, 1993), o Brasil lançou, em 2006, o Plano Nacional de Promoção da Saúde, pois se tornou evidente a necessidade de configurar uma política pública capaz de atender aos desafios dos problemas de saúde da população. Na perspectiva dos documentos internacionais, a Promoção da Saúde visa o fortalecimento de uma política transversal, integrada e intersetorial, compondo redes de compromisso e corresponsabilidade na formulação de propostas e ações para garantir a qualidade de vida da população. Como afirma o documento brasileiro, para isso deve haver uma articulação "sujeito/coletivo, público/privado, Estado/sociedade, clínica/política, setor sanitário/outros setores, visando romper com a excessiva fragmentação na abordagem do processo saúde-adoecimento e reduzir a vulnerabilidade, os riscos e os danos que nele se produzem" (BRASIL, 2006, p. 15).

A saúde deve ser vista como um conceito positivo, que enfatiza os recursos sociais, naturais e pessoais, e promovê-la não é responsabilidade exclusiva do setor de saúde, mas dos vários setores da sociedade, em particular os que atuam na formação e informação da população. Com isso, o que se espera é que aumentem as opções de circulação de informações para que a população possa exercer maior controle sobre sua própria saúde e adotar hábitos de vida mais saudáveis.

A partir deste "pano de fundo", o grupo de pesquisa propôs uma linha de atuação voltada para a criação de estratégias educacionais e comunicacionais para o público jovem. Fomos estimulados a atuar com essa parcela da população pela ampla discussão acerca das transformações relacionadas à crescente modernização e urbanização, as quais estão associadas a mudanças no estilo de vida que favorecem o desenvolvimento das doenças crônicas não transmissíveis. O público jovem, em particular os adolescentes, é um dos mais vulneráveis em função dos apelos mercadológicos, especialmente, para o consumo de produtos comestíveis industrializados que são largamente ofertados em todos os espaços coletivos. Isso faz com que a questão alimentar seja estratégica para a saúde pública, afinal, a alimentação define a qualidade de vida nas fases posteriores da vida, em particular na terceira idade. É sabido que, atualmente, a obesidade entre os jovens brasileiros é encontrada nas diferentes faixas econômicas, principalmente naquelas de classe mais alta, fato que pode ser explicado em função de que a "[...] classe socioeconômica influencia a obesidade por meio da educação, da renda e da ocupação, resultando em padrões comportamentais específicos que afetam ingestão calórica, gasto energético e taxa de metabolismo" (MELLO; LUFT; MEYER, 2004, p. 173-174). 
Com isso, é de extrema relevância que as comunidades e instituições sociais incorporem práticas educativas voltadas à promoção da saúde dos jovens, tendo em vista o impacto que isso pode gerar futuramente sobre a saúde pública. Porém, um dos desafios é propor ações que operem a partir das estratégias mais amplas definidas em Ottawa (BRASIL, 2006), e associadas às diretrizes propostas pelo Ministério da Saúde na Política Nacional de Promoção da Saúde, a saber: a integralidade, a equidade, a responsabilidade sanitária, a mobilização e participação social, a intersetorialidade, a informação, educação e comunicação e, por fim, a sustentabilidade. A partir desse entendimento, o grupo buscou compreender inicialmente o conceito de "rede social digital" e, concomitantemente, realizou uma pesquisa bibliográfica para identificar o que já vinha sendo pesquisado sobre o tema.

\section{Refletindo sobre as redes sociais digitais}

Mas, por que as redes sociais? Porque a cada dia cresce a crença de que as tecnologias de comunicação em rede podem ser uma ferramenta eficiente para promover a comunicação, pois se constituem na ferramenta mais poderosa de circulação de informação da contemporaneidade. Para Lemos (2003), este momento é caracterizado pela cibercultura, que se consolidou entre as décadas de 1980 e 1990 com a informática de massa e a popularização da internet, que ganhou força após a criação da world wide web (www), em 1991.

As novas tecnologias permitiram a criação de meios de comunicação mais interativos, liberando os indivíduos das limitações de espaço e tempo, tornando a comunicação mais flexível. Com apenas um clique, qualquer pessoa pode acessar uma informação específica e manter contato com pessoas que estão distantes. Os jovens nascidos após 1995 são "nativos" da cibercultura, inseridos num modelo de comunicação com equipamentos que operam por meio da convergência de mídias. É a tradução da tecnocultura, definida por Muniz Sodré (2005), como um processo em que as trocas simbólicas que viabilizam a comunicação de qualquer natureza são mediadas por signos estritamente vinculados à evolução tecnológica.

É importante também lembrar que esse cenário é alicerçado na ideia da participação (KOTLER, 2010). Segundo o autor, em decorrência do fácil acesso às informações e às tecnologias de comunicação, as pessoas passaram a ter mais liberdade para expressar suas opiniões, podem participam de forma ativa dentro das mobilizações e trocar informações constantemente. Este cenário coloca o desafio para os profissionais da comunicação que precisam não só proporcionar experiências empolgantes para o público, mas também buscar a transformação da sociedade.

Além dessas questões, devemos considerar também que o Brasil ficou em quinto lugar no ranking mundial, quando analisado o meio onde as pessoas mais 
procuram orientações sobre saúde: na internet. Esse dado foi revelado numa pesquisa da Bupa Health Pulse, publicada no jornal O Globo, em janeiro de 2011. Entre os países pesquisados - Brasil, Austrália, Grã-Bretanha, China, França, Alemanha, Índia, Itália, México, Rússia, Espanha e Estados Unidos - foi identificado que $81 \%$ das pessoas que têm acesso à internet usam a rede para obter orientações sobre saúde, remédios ou condições que necessitem cuidados médicos. Esses dados por si nos colocam o desafio de garantir que seja disponibilizada à população informação de qualidade. Em função desses e outros aspectos é que definimos que a plataforma mais adequada às ações de Promoção da Saúde do jovem são as redes sociais digitais.

Mas o que são essas redes sociais digitais? O termo "rede social" tornou-se sinônimo de tecnologia da informação e comunicação; seu uso transcorreu áreas e destruiu fronteiras sendo apropriado, hoje, por muitos atores sociais. Uma das apropriações mais intensas deu-se no campo da comunicação - mas não exclusivamente - com o uso de termos como rede social digital, mídia social, mídia digital, entre outros, para expressar o fenômeno em questão. Esse foi o primeiro desafio com que o grupo teve que lidar, pois diante de imensidade de termos para designar (quase) a mesma coisa, foi necessário um tempo para estabelecer uma base conceitual que pudesse orientar os trabalhos. Passemos à discussão do conceito.

Segundo Santaella (2003), foi por volta do início dos anos de 1990 que, num sentido mais estrito, mídia se referia especificamente aos meios de comunicação de massa, especialmente aos meios de transmissão de notícias e informação, tais como jornais, rádio, revistas e televisão. Também se passou a chamar de mídias todos os meios de que a publicidade se serve, desde outdoors até as mensagens publicitárias veiculadas por jornal, rádio, TV. Em todos esses sentidos, a palavra "mídia" se referia aos meios de comunicação de massa. A semioticista lembra, ainda, que o termo foi se fixando, cada vez mais, em função do crescimento acelerado dos meios que não podem mais ser considerados necessariamente como de comunicação de massa. Segundo a autora:

A emergência da cultura planetária via redes de teleinformática instalou definitivamente uma crise na hegemonia dos meios de massa e, com ela, o emprego da palavra "mídia" se generalizou para se referir também a todos os processos de comunicação mediados por computador. A partir de uma tal generalização, todos os meios de comunicação, inclusive os de massa, inclusive o livro, inclusive a fala, passaram a ser referidos pela rubrica de "mídia" até o ponto de qualquer meio de comunicação receber hoje a denominação genérica de "mídia" e o conjunto deles, de mídias. (SANTAELLA, 2004, p. 76)

Nesse mesmo período, nos Estados Unidos, teóricos e intelectuais acadêmicos que utilizavam os processos de comunicação integrados por sistemas digitais informatizados expandiam o emprego do termo mídia e passavam a chamar esses suportes de novos meios de comunicação, de as "novas mídias". Ou seja, o termo surgiu para: 
[...] marcar a passagem dos meios de massa aos meios digitais e as diferenças que essa passagem implic[ou]. [...] muito mais comum tem sido o emprego da expressão new media em oposição a mass media. Portanto, em inglês, a expressão new media surgiu para dar conta de uma expansão dos meios de comunicação para além dos meios estritamente de massa. (SANTAELLA, 2003, p. 78)

Straubhaar e LaRose (2004) também registraram uma preocupação sobre isso, pois vários termos eram utilizados para descrever essa convergência de tecnologias. Segundo os autores,

\begin{abstract}
Nos últimos tempos prolifera uma variedade de neologismos, slogans e acrônimos que descrevem de uma maneira ou de outra a convergência entre meios de comunicação e computadores: videotexto, rede inteligente, internet, multimídia, novos meios, marketing direcionado, nação cabeada, mídia interativa [...] - e assim por diante. Não está claro qual desses termos vai predominar (ou se algum novo vai roubar a cena!). (2004, p. 89)
\end{abstract}

Lev Manovich (apud LEÃO, 2005), nesse mesmo sentido, teorizou acerca do termo mídia no ciberespaço. Para ele, as novas mídias "ocupam-se" de objetos criados e editados no computador e, além disso, usam essa tecnologia como forma de distribuição. Já Wilson Dizard Jr. (2000) afirma que a chamada "nova mídia" não é apenas uma extensão linear da antiga. A mídia clássica e a nova mídia oferecem recursos de informação e entretenimento para grandes públicos, de maneira conveniente e a preços competitivos. A diferença é que a "nova mídia" está expandindo dramaticamente a gama de recursos disponíveis para os consumidores através da internet e de outros canais. Contudo, o mesmo autor alerta para o fato de que as velhas mídias já foram consideradas novas e não eram digitais. Eram eletrônicas e de massa. E indaga se esse conceito de novas mídias também não seria algo incorreto, já que pode se tornar defasado com o tempo e ter que ser modificado assim que cada nova mídia surgir. Se compreendermos a dinâmica econômico-produtiva do sistema capitalista, é bem provável que isso aconteça, pois é intrínseco a esse sistema econômico a necessidade de geração de novos produtos, novas necessidades e desejos para movimentar a máquina produtiva (HARVEY, 1994).

O fato é que houve uma mudança significativa na estrutura de comunicação com os recursos disponibilizados pela internet. Os autores norte-americanos Straubhaar e LaRose (op. cit.) explicam que o termo mídia foi usado como livre tradução para o conceito de meios de massa e que, se o computador for considerado um novo meio de massa, a concepção de meios de massa que era estudada até então pelos clássicos da comunicação não pode ser mais aplicada nos dias de hoje. Isso porque meios de massa se baseiam no sistema de broadcasting, o qual "emite" um mesmo conteúdo gerado por um veículo para muitos, sem possibilidade de interferência do espectador ou feedback. Concordamos com os autores no sentido de que 
isso não acontece na nova mídia, esteja ou não correto esse termo. O que temos com as ferramentas de comunicação baseadas na rede internet é um sistema de selfcasting, onde cada um produz e consome conteúdo, a estrutura é de muitos para muitos. A unidade de análise comunicacional passa a ser o sujeito, tanto na dinâmica de criação quanto de consumo de conteúdo.

Para dar conta desta questão, alguns autores estão utilizando o termo "mídia digital", que tem como característica principal a convergência de meios num sistema de rede, e este conceito de rede é específico. Não é a da imprensa física de ampla circulação, seja ela rádio, televisão, cabos e satélites, tal como aquela topologia de rede tecida pelo mass media, que era singularizada pela presença de centros, pela informação em comum e por canais fixos e fechados de distribuição de mensagens, que tendiam à centralização (BRANCO; MATSUZAKI, 2009). Os autores estão tratando aqui da rede mundial de computadores.

Em particular para a área da comunicação, a necessidade de uma recomposição terminológica é emergente. No universo e na economia da informação em rede, cada indivíduo é livre para observar, responder, questionar e debater, não apenas em princípio, mas na capacidade. A audiência não se limita mais a apenas ler, ouvir e assistir, é possível participar do debate (BENKLER, 2006). Neste contexto, Katri e Esa (2008) defendem que social media (expressão em inglês) é o termo mais apropriado para descrever serviços da web que recebem conteúdo dos usuários ou que agregam conteúdo de outros sites. Acrescentam ainda que, numa mídia social, qualquer um pode ser um produtor de conteúdo, e os chamados "software sociais" trouxeram para a sociedade sistemas de gerenciamento de conteúdo que antigamente só grandes empresas podiam ter. Isso rompeu com o modelo centralizado de produção de conteúdo e, portanto, da estrutura comunicacional mediada, socializando o processo.

Nesse mesmo sentido, Becker, Naaman e Gravano (2009) acrescentam que sites de "mídia social" nada mais são do que sistemas populares de distribuição de notícias e outros conteúdos de interesse pessoal. Eles vêm sendo usados com uma ferramenta online, uma plataforma para o compartilhamento de opiniões, percepções, experiência e perspectivas, em mensagens que utilizam texto, imagens, áudio e vídeo (THEVENO, 2007). Esse conteúdo pode ser hospedado em sites populares como Facebook, Twitter, YouTube e Wikipedia e blogs (GREYSEN; KIND; CHRETIEN, 2010) e, em termos de estrutura tecnológica, passam a usar tecnologias móveis e web-based, fazendo surgir plataformas altamente interativas, por meio das quais os indivíduos e comunidades podem colaborar para criar, discutir e modificar conteúdo gerado por qualquer usuário (KAPLAN; HAENLEIN, 2010; SCHROCK, 2009; KIETZMANN et al., 2011). Isso marcou a segunda geração de serviços na rede: a Web 2.0, a qual ampliou as formas de produzir a compartilhar informações online (PRIMO, 2006). 
Branco e Matsuzaki (2009) transportam a questão para o cenário brasileiro, propondo que o termo social media, traduzido para o português como "mídia social", seja utilizado para caracterizar o uso do meio eletrônico para interação entre pessoas, combinando textos, imagens, sons e vídeo, os quais possibilitam criar uma interação social de compartilhamento de experiências, construídas com base nos fundamentos ideológicos e tecnológicos da Web 2.0.

Quem adota o termo "redes", como os autores Pretto e Silveira (2008), lembra que este tem servido como metáfora para a reflexão sobre princípios de organização social, política, econômica, cultural e educacional. A palavra vem do latim retis, que significa entrelaçamento de fios com aberturas regulares que formam uma espécie de tecido. Por isso seu emprego em diferentes situações e em aplicações nos mais diversos campos de conhecimento. Segundo os autores, quando se trata de ferramentas disponibilizadas pela internet, atualmente, "[...] a noção de rede diz respeito a um princípio de organização de sistemas, o qual envolve as redes tecnológicas, as redes sociais, as redes acadêmicas e, claro, as redes das redes, gerando conhecimentos que podem contribuir para uma maior integração de ações e conhecimentos" (PRETTO; SILVEIRA, op. cit., p. 76).

Por outro lado, Cornu (apud MARTELETO, 2010) defende que há três planos básicos de redes existentes nos dias de hoje: a rede tecnológica (mecanismos e ferramentas de informática); a rede semântica (relações, elos, estratégias, entre outros); a rede humana (interações de pessoas). Todas influenciam os procedimentos intelectuais e as relações sociais. Com base nesse entendimento, o autor conclui que as redes sociais são, "cada vez mais, favorecidas pelas tecnologias de informação e comunicação, ao ampliarem o espectro da cultura e do mundo vivido territorialmente pelos sujeitos sociais" (CORNU, op. cit., p. 33).

Branco e Matsuzaki (2009) lembram que o ser humano é, antes de tudo, um ser social e defendem que as "redes sociais", no ambiente digital, são ferramentas que estão simplesmente potencializando essa tendência e alterando completamente as possibilidades de comunicação. Seja por meio de sites de serviços, que permitem aos indivíduos construir um perfil público, articular, ver e pesquisar listas de usuários com quem compartilhar uma conexão (BOYD; ELLISON, 2007), seja constituindo relações interpessoais mediadas pelo computador, o que faz é interagir buscando fundamentalmente a comunicação (FREITAS, 2010).

Santana et al. (2009, p. 340) propõem as chamadas Redes Sociais Online (RSO) como sendo

[...] um sistema eletrônico de comunicação de alcance global que possibilita a integração de todos os meios de comunicação e que possui interatividade potencial [e] suscitam a participação dos envolvidos para compartilhar informações, fatos e experiências relacionadas ao evento. 
Outro autor, Costa (2005), optou por batizar esses suportes de "redes digitais". Estes são definidos como um sistema informal de troca, o que, segundo ele, transmutou o conceito de "comunidade" para o de "rede social" em função, principalmente, da multiplicação das ferramentas de colaboração online e das tecnologias de comunicação móvel, as quais se integraram às mídias tradicionais. Esse movimento levou a uma incorporação da comunidade à rede social, entendida aqui como um conjunto de sujeitos interagindo por meio das tecnologias digitais online.

Ampliando essa ideia, Machado e Tijiboy (2005) denominam de "softwares sociais" as ferramentas que sustentam essas redes - e-mails, fóruns, listas de discussão, sistemas de boletins eletrônicos (BBS), grupos de notícias, chats, softwares sociais como Orkut, Facebook, Muvuca, entre outros, os quais funcionam como mediadores sociais. Segundo os autores,

\begin{abstract}
Estes canais de comunicação e seus suportes tecnológicos, embora necessários para o funcionamento das trocas comunicativas, não podem ser confundidos como sendo a própria comunidade virtual. [...] Nos softwares sociais, as comunidades funcionam como uma moderna lista de discussão, porém mais personalizada, no qual os laços sociais (os amigos/friends) agenciam e potencializam as conexões de cada um com todos os demais [...]. Esta grande rede cooperativa, que se distribui rizomaticamente e de forma imprevisível, gera espaços de construção de subjetividades e [...] ao mesmo tempo em que valoriza o individual dentro da coletividade, favorece a percepção de conexão planetária, de que todos, de uma certa forma, estão conectados uns aos outros por laços relacionais. (p. 3)
\end{abstract}

Em resumo, no cibermundo (LEMOS, 2003), a convergência da tecnologia digital com o universo da mídia que se configura na tela dos computadores, por meio do sistema de linguagem amigável da web, fez com que o conceito de mídia extrapolasse o do mundo atômico ou analógico. Não é mais meio de transmissão, mas os vários sistemas que viabilizam o compartilhamento das mais diferentes informações, nos mais diversos códigos, em formas distintas de comunicação: uni, bi e/ou multidirecional.

Numa pesquisa informal junto aos pesquisadores espalhados pelas Américas, Europa e Estados Unidos, com os quais o grupo de pesquisa tem relações, o termo mais corrente adotado nos países da América Latina, Portugal, França e Espanha é o de "rede social digital". Nos Estados Unidos é que mais comumente as redes são chamadas de social media. Porém, encontram-se na literatura também os termos: social networks, mídia social e sosiaalinenmedia, este último na Finlândia. Diante da complexidade e diversidade conceitual e, também, das práticas em torno do que seja a nova configuração tecnológica da internet e seu impacto nos processos comunicacionais, o grupo de pesquisa compreendeu que o conceito que melhor expressa o aparato tecnológico e os processos comunicacionais realizados a partir dessa base física está sob a rubrica de "rede social digital". 
Em síntese, o grupo formulou o conceito de "rede social digital" como a macroestrutura tecnológica que dá suporte a um conjunto de atores sociais (sujeitos e instituições) conectados por laços sociais (BATISTA, 2012; RAHME, 2010; FREUD, 1976, 1997), os quais são formados, mantidos e reforçados (ou não) por meio de interações sociais (VYGOTSKY, 1989, 1987; BAKHTIN, 1988; LURIA, 1987). As interações são concretizadas, realizadas dentro de uma relação de troca de conteúdos. Estes podem ser criados pelas mais diferentes linguagens disponíveis no formato digital: textual, sonora, audiovisual e imagética. Estas ferramentas potencializam a manutenção e a expansão dos laços sociais, além de ajudarem a visualizar as redes de relacionamento das quais cada sujeito faz parte.

Com a formulação do conceito, passamos à segunda etapa da pesquisa: analisar a bibliografia levantada sobre o tema das redes sociais digitais e os jovens, cujo resultado apresentamos a seguir.

\section{Perfil da produção bibliográfica sobre redes sociais digitais e os jovens}

Para o levantamento da bibliografia (artigos em revista científica, teses e dissertações), definimos os seguintes procedimentos de pesquisa:

1) Buscar em bases de dados digitais textos publicados entre 2001 a 2011 sobre a temática das redes sociais digitais. Nesta etapa, era nosso objetivo manter a proximidade com a área da saúde. Contudo, o número de textos encontrados foi muito pequeno e, por isso, realizamos as pesquisas sem excluir as demais áreas do conhecimento;

2) Dos textos identificados, selecionar pelo título e resumo aqueles com aderência à temática: redes sociais digitais e jovem. Entre os mais de 300 textos selecionados, aqueles que tratavam especificamente do público jovem também eram em número reduzido. Isso levou o grupo a adotar um procedimento mais aberto em relação à seleção dos textos: definimos que seriam lidos todos aqueles que tratassem das redes sociais digitais, a partir dos conceitos mais utilizados pelas áreas.

3) Após a seleção final, foi feita a leitura integral para identificar as categorias descritivas e traçar um perfil dessa produção.

As bases de dados pesquisadas foram: Biblioteca Virtual da Saúde, Lilacs, Ibecs, MedLine, Scielo, Portal da Capes, do Cesumar e da UEM. Para as buscas, definimos as seguintes palavras-chave: Educação, Comunicação, Tecnologia da informação, Promoção da saúde, Redes sociais e Web 2.0. Diante da diversidade conceitual, conforme discutido anteriormente, a busca nas bases de dados digitais tornou-se uma tarefa 
complexa. Não foi possível utilizar somente o termo "redes sociais" ou "redes sociais digitais". Com o primeiro, aparecia todo o qualquer tipo de trabalho sobre rede social, a imensa maioria sem qualquer relação com a tecnologia; o segundo termo era restrito demais e o resultado das buscas não atendia nossas necessidades. Isso ocorreu, por exemplo, porque na área da saúde as "redes sociais" compreendem estratégias de atuação dos profissionais da saúde em comunidades, sem necessariamente significar qualquer vínculo com o uso de tecnologia. Com isso, optamos por utilizar palavras-chave que estariam inseridas nos textos e, por meio do uso de conectivos lógicos, ir refinando os resultados parciais. Assim, nosso primeiro levantamento chegou a mais de um milhão de textos e fomos, sucessivamente, refinando a seleção até chegar em 49 artigos e 115 teses/dissertações. Devido às limitações deste artigo, apresentaremos somente alguns resultados acerca do perfil dessa produção.

Um dos resultados que consideramos importante trazer diz respeito aos sujeitos que foram pesquisados. É relevante salientar que por "sujeito" compreendemos a pessoa, a instituição, a teoria, o sistema, a ferramenta etc., de quem, ou de onde, ou do que foram extraídos os dados/informações para a pesquisa que gerou o texto. Os resultados estão na Tabela 1.

Para nossos propósitos foi importante identificar que os "jovens" aparecem entre os sujeitos mais pesquisados quando o assunto é "rede social digital". Representaram 38,8\% ${ }^{1}$ dos artigos e 14,8\% das teses/dissertações, sedimentando um pouco mais nossa tese de que o uso das redes sociais digitais para a promoção da saúde dessa população pode ser uma estratégia interessante, apesar de ainda termos poucos dados sobre os resultados dessas estratégias. Estudos sobre as redes sociais digitais em si ocuparam o segundo lugar em termos de foco da pesquisa.

Entre os artigos, dos 19 textos em que o sujeito era o jovem, sete foram de pesquisas da área de Educação, dois da Antropologia, e um texto em cada uma das áreas de Ciência da Informação, Ciência Política, Ciências da Saúde, Linguística e Sociologia. Na área de Comunicação não encontramos nenhum texto cuja temática tenha sido abordada pela ótica do jovem, mas sim a partir do próprio meio. De todos os textos da área de Comunicação, 60\% dos artigos analisaram a rede social em si. Quanto ao conteúdo desses artigos, desse conjunto, sinteticamente, a produção analisou o uso de ferramentas pelos jovens, identificando os modelos de rede e como isso afetou a organização da rede. Por outro lado, analisou historicamente como a comunicação entre as pessoas mudou e como os jovens pensam e usam os novos recursos, indicando que existe uma forma de cooperação na troca de saberes e que, na formação de redes sociais, existe uma influência de ideias e informações por meio dessas novas formas de associações humanas. Também é interessante indicar que foi apontada a necessidade de ações para a promoção da inclusão digital, a partir das características brasileiras, pois isso tem se mostrado uma realidade. 
Tabela 1

Distribuição quanto aos sujeitos identificados nos artigos e teses/dissertações

\begin{tabular}{|l|c|c|c|c|}
\hline \multirow{2}{*}{ Sujeito } & \multicolumn{2}{|c|}{ Artigos } & \multicolumn{2}{c|}{ Teses/Dissertações } \\
\cline { 2 - 5 } & Freq. & $\%$ & Freq. & $\%$ \\
\hline Jovens & 19 & $38,80 \%$ & 17 & $14,80 \%$ \\
\hline Rede Social & 12 & $24,50 \%$ & 20 & $17,40 \%$ \\
\hline Cibercultura & 10 & $20,40 \%$ & 21 & $18,30 \%$ \\
\hline Produção Cultural & 5 & $10,20 \%$ & 1 & $0,90 \%$ \\
\hline Sistemas de Informação & 5 & $10,20 \%$ & 16 & $13,90 \%$ \\
\hline Educadores & 4 & $8,20 \%$ & 7 & $6,10 \%$ \\
\hline Políticas Governamentais & 3 & $6,10 \%$ & 6 & $5,20 \%$ \\
\hline Instituições & 1 & $2,00 \%$ & 2 & $1,70 \%$ \\
\hline Produção Teórica & 2 & $4,10 \%$ & 4 & $3,50 \%$ \\
\hline Profissional de Outras Áreas & 1 & $2,00 \%$ & 7 & $6,10 \%$ \\
\hline Meio Ambiente & 1 & $2,00 \%$ & 0 & $0 \%$ \\
\hline Alunos & 0 & $0 \%$ & 8 & $7,00 \%$ \\
\hline Internet/Ferramentas de Interação & 0 & $0 \%$ & 8 & $7,00 \%$ \\
\hline Sistemas de Comunicação & 0 & $0 \%$ & 7 & $6,10 \%$ \\
\hline Educação & 0 & $0 \%$ & 3 & $2,60 \%$ \\
\hline Sociedade & 0 & $0 \%$ & 3 & $2,60 \%$ \\
\hline Mulheres & 0 & $0 \%$ & 2 & $1,70 \%$ \\
\hline Idosos & 0 & $0 \%$ & 1 & $0,90 \%$ \\
\hline Empresas & 0 & $0 \%$ & 1 & $0,90 \%$ \\
\hline Comunidades Carentes & 0 & $0 \%$ & 1 & $0,90 \%$ \\
\hline Gestores Públicos & 0 & $0 \%$ & 1 & $0,90 \%$ \\
\hline Agentes de Saúde & 49 & $0 \%$ & 1 & $0,90 \%$ \\
\hline TOTAL OBS. & & 115 & \\
\hline & 0 & & \\
\hline
\end{tabular}

Nas teses e dissertações, a Educação também foi a área que mais se debruçou em analisar as redes sociais digitais sob a ótica do jovem, com 46,7\%, do total de 17 trabalhos. Em termos de conteúdo, as pesquisas foram sobre as formas de uso da rede em favor do jovem e para melhoria da aprendizagem; também identificou a emergência de comportamentos associados a novas práticas sociais, fenômeno importante para se averiguar, tendo em vista a organização dos currículos escolares. Também os textos mostraram que existe uma população que busca acesso em espaços comunitários e como essa prática está se ampliando para outras faixas etárias. Em relação à educação, as pesquisas se voltaram para analisar o movimento crescente que aponta tanto para a 
constituição de uma comunidade de aprendizagem, quanto para os recuos da mesma; aponta também para a criação de cursos oferecidos pelas redes sociais digitais e de formas do sujeito se colocar neste espaço, indicando que existe diferença entre a escrita para si, a escrita para outro e a escrita na e para escola, dependendo do suporte utilizado. E, finalmente, algumas pesquisas envolvendo os jovens se preocuparam com a dimensão subjetiva e os movimentos desencadeados na instituição escolar com a chegada dos ambientes informatizados. As pesquisas realizadas nestes trabalhos focaram mais a relação e o uso da rede em si, e não tanto os impactos que esse uso pode trazer a esses sujeitos. Especificamente tratando das redes sociais digitais, pela área da saúde e com o público jovem, entre os artigos, somente um abordou o uso das redes sociais digitais para promover a saúde do jovem, indicando que existe uma potencialidade a ser descoberta, e uma dissertação que abordou a questão da gravidez na adolescência, com análise de uma experiência em termos de diagnóstico.

Outro dado interessante diz respeito à distribuição quanto às áreas de origem dessas pesquisas. Na Tabela 2 apresentamos a distribuição:

\section{Tabela 2}

Distribuição dos artigos e teses/dissertações pelas áreas do conhecimento

\begin{tabular}{|l|c|c|c|c|}
\hline \multirow{2}{*}{ Área da Ciência } & \multicolumn{2}{|c|}{ Artigos } & \multicolumn{2}{c|}{ Teses/Dissertações } \\
\cline { 2 - 5 } & Freq. & $\%$ & Freq. & $\%$ \\
\hline Ciências da Comunicação & 10 & $20,40 \%$ & 29 & $25,20 \%$ \\
\hline Educação & 10 & $20,40 \%$ & 30 & $26,10 \%$ \\
\hline Antropologia & 7 & $14,30 \%$ & 2 & $1,70 \%$ \\
\hline Ciência da Informação & 7 & $14,30 \%$ & 13 & $11,30 \%$ \\
\hline Ciências da Saúde & 6 & $12,20 \%$ & 2 & $1,70 \%$ \\
\hline Ciência Política & 3 & $6,10 \%$ & & \\
\hline Ciências da Computação & 3 & $6,10 \%$ & 15 & $13,00 \%$ \\
\hline Linguística & 2 & $4,10 \%$ & 2 & $1,70 \%$ \\
\hline Sociologia & 1 & $2,00 \%$ & 0 & $0 \%$ \\
\hline Administração & 0 & $0 \%$ & 5 & $4,30 \%$ \\
\hline Artes Visuais & 0 & $0 \%$ & 6 & $5,20 \%$ \\
\hline Ciências Sociais & 0 & $0 \%$ & 3 & $2,60 \%$ \\
\hline Design & 0 & $0 \%$ & 1 & $0,90 \%$ \\
\hline Engenharias & 0 & $0 \%$ & 2 & $1,70 \%$ \\
\hline Geografia & 0 & $0 \%$ & 1 & $0,90 \%$ \\
\hline Letras & 0 & $0 \%$ & 1 & $0,90 \%$ \\
\hline Idosos & 0 & $0 \%$ & 3 & $2,60 \%$ \\
\hline TOTAL OBS. & 49 & $100 \%$ & 115 & $100 \%$ \\
\hline
\end{tabular}


Indiscutivelmente, as áreas da Educação e Comunicação foram as que mais apresentaram pesquisas sobre o tema. As bases de dados pesquisadas indicam que a interferência sobre os processos comunicacionais e educacionais tem levado os pesquisadores a se debruçar sobre o fenômeno. Isso pode nos apontar para o fato de que há certo consenso sobre as redes sociais digitais serem um canal vinculado ao público jovem. Talvez, por apresentarem-se como espaços dinâmicos, baseados em diálogo, com uma alta mobilidade.

\section{Considerações finais}

Com um smartphone à mão, todo tipo de comunicação é quase instantânea, mensagens podem ser encaminhadas a qualquer momento, por/para qualquer pessoa. E, sob este aspecto, podem ser ferramentas de processos de comunicação com vistas à educação e à promoção da saúde em rede. Sem dúvida, há muito ainda o que explorar no que diz respeito à utilização das redes em estratégias de comunicação junto aos jovens.

Contudo, é importante considerar que há uma séria demanda pela organização de processos de comunicação que estejam em sintonia com as novas perspectivas de rede. É necessário identificar efetivamente o que precisa ser dito e rever como o conteúdo deve ser veiculado ou disponibilizado nas redes sociais digitais, criando regras que garantam a possibilidade de identificar oportunidades e oferecer os conteúdos que se quer, no nosso caso, para promover a saúde. Isso quer dizer que é preciso inovar nos processos a partir de investimentos em pesquisas sobre novas estratégias comunicacionais e educacionais. Ambas as áreas - Educação e Comunicação - vêm sofrendo impactos, em maior ou menor grau, seja pela desconfiguração de seu quadro teórico-conceitual, seja pelas problemáticas em torno dos processos de ensino-aprendizagem que sofrem alterações a partir do uso continuado dessas tecnologias pelos jovens, interferindo na cognição. Segundo a tese Blog: da internet à sala de aula, de Carmen Pimentel, defendida no Programa de Pós-Graduação em Letras da Universidade do Estado do Rio de Janeiro (Uerj), qualquer disciplina pode e deve usar a tecnologia a favor da aprendizagem. "Se o aluno e o professor perceberem que têm uma ferramenta em suas mãos que pode auxiliar na construção do aprendizado, a educação só ganhará com isso. Conta, aqui, a criatividade do educador!" (PIMENTEL, 2010, página). No nosso caso, o educador para a saúde.

É nesta perspectiva que estamos apostando. Os dados dessa primeira etapa da pesquisa nos mostraram que a produção sobre o tema (redes sociais digitais e jovens) no Brasil ainda é insuficiente, e, mais ainda, para o uso das mesmas para a área da saúde. É uma lacuna que vale a pena procurar diminuir, pois se tivermos 
estratégias comunicacionais e educacionais consolidadas e exitosas, poderemos contribuir sobremaneira para a saúde pública brasileira.

Outro aspecto que vale a pena ressaltar é a prática de pesquisa num "espaço" interdisciplinar. $\mathrm{O}$ fato de nós, pesquisadores, termos origem em uma diversidade de áreas não foi nenhum empecilho para trabalharmos juntos de forma exitosa. Ao contrário: foi (e vem sendo) fundamental para o sucesso das pesquisas que realizamos juntos no campo interdisciplinar da Promoção da Saúde.

\section{Nota}

1. Por se tratar de uma análise estatística descritiva a partir da análise de conteúdo (GIBBS, 2009), visando identificar um perfil, não foram realizados testes estatísticos para verificar se as diferenças de percentuais são significativas, pois isso fugia aos nossos propósitos.

\section{Referências}

BAKHTIN, M. Marxismo e filosofia da linguagem. São Paulo: Hucitec, 1988.

BATISTA, A.A.G. Notas sobre a reflexão sociológica da psicanálise. Disponível em: $<$ http:// www.institutopsicanalise-mg.com.br/psicanalise/almanaque/04/textos/A\%20 reflex\%C3\%A3o\%20social.pdf>. Acesso em: 10 ago. 2012.

BECKER H.; NAAMAN M.; GRAVANO L. Event identification in social media. In: INTERNATIONAL WORKSHOP ON THE WEB AND DATABASES, 12., 2009, Providence. Proceedings of... Providence, 2009.

BENKLER, Y. The wealth of networks: how social production transforms markets and freedom. New Haven: Yale University, 2006.

BOYD, D.M.; ELLISON, N.B. Social network sites: definition, history, and scholarship. Journal of Computer-Mediated Communication, v. 13, n. 1, p. 210-230, 2007. Disponível em: $<$ http://jcmc.indiana.edu/vol13/issue1/boyd.ellison.html>. Acesso em: 3 dez. 2011.

BRANCO, C.F.; MATSUZAKI, L. Olhares da rede. São Paulo: Momento, 2009. Disponível em: <http://www.culturaderede.com.br>. Acesso em: 3 dez. 2011.

BRASIL. Ministério da Saúde. Secretaria de Vigilância em Saúde. Política Nacional de Promoção da Saúde. Brasília, DF: Ministério da Saúde, 2006.

BRASILEIROS estão em quarto lugar na busca por informações sobre saúde na internet. O Globo, Rio de Janeiro, 4 jan. 2011. Caderno Saúde. Disponível em: <http://oglobo. globo.com/saude/brasileiros-estao-em-quarto-lugar-na-busca-por-informacoes-sobresaude-na-internet-segundo-2842913\#ixzz24JPuXWff>. Acesso em: 15 mar. 2011. 
COSTA, R. Por um novo conceito de comunidade: redes sociais, comunidades pessoais, inteligência coletiva. Interface: Comunicação, Saúde, Educação, Botucatu, v. 9, n. 17, p. 235-48, mar./ago. 2005.

DIZARD JUNIOR, W. A nova mídia: a comunicação de massa na era da informação. Rio de Janeiro: Zahar, 2000.

FREITAS, V. Redes sociais, mídias sociais e mídias digitais: qual a diferença? 2010. Disponível em: <http://gutomodesto.com.br/redes-sociais-midias-sociais-e-midias-digitaisqual-a-diferenca/>. Acesso em: mar. 2012.

FREUD, S. Psicologia de grupo e a análise do ego. In: FREUD, S. Obras psicológicas completas de Sigmund Freud. Rio de Janeiro: Imago, [1921] 1976. v. 18.

FREUD, S. O mal-estar na civilização. Rio de Janeiro: Imago, 1997.

GIBBS, G. Análise de dados qualitativos. Porto Alegre: Artmed, 2009.

GREYSEN, S.R.; KIND, T.; CHRETIEN, K.C. Online professionalism and the mirror of social media. Journal of General Internal Medicine, v. 25, n. 11, p. 1227-1229, nov. 2010.

HARVEY, D. Condição pós-moderna: uma pesquisa sobre as origens da mudança cultural. 4. ed. Trad. de A. U. Sobral e M. S. Gonçalves. São Paulo: Loyola, 1994.

KAPLAN, A.M.; HAENLEIN, M. Users of the world, unite!: the challenges and opportunities of Social Media. Business Horizons, Bloomington, v. 53, n. 1, p. 59-68, 2010. Disponível em: <http://www.sciencedirect.com/science/article/pii/S0007681309001232>. Acesso em: 12 jul. 2012.

KATRI, L.; ESA, S. Social media: introduction to the tools and processes of participatory economy. Tampere: University of Tampere, 2008. Disponível em: <http://tampub.uta. fi/english/tulos.php?tiedot=231>. Acesso em: 3 dez. 2011.

KIETZMANN, J.H. et al. Social media?: get serious! Understanding the functional building blocks of social media. Business Horizons, Bloomington, v. 54, n. 3, p. 241251, 2011.

KOTLER, P. Marketing 3.0: as forças que estão definindo o novo marketing centrado no ser humano. Rio de Janeiro: Elsevier, 2010.

LEÃO, L. (Org.). O chip e o caleidoscópio: reflexões sobre novas mídias. São Paulo: Senac, 2005.

LEMOS, A. Cibercultura: alguns pontos para compreender a nossa época. In: LEMOS, A.; CUNHA, P. (Org.). Olhares sobre a cibercultura. Porto Alegre: Sulina, 2003.

LURIA, A.R. Pensamento e linguagem. Porto Alegre: Artmed, 1987. 
MACHADO, J.R.; TIJIBOY, A.V. Redes sociais virtuais: um espaço para efetivação da aprendizagem cooperativa. Novas Tecnologias na Educação, Porto Alegre, v. 3, n. 1, maio, 2005. Disponível em: <http://www.inf.ufes.br/ cvnascimento/artigos/ a37_redessociaisvirtuais.pdf >. Acesso em: 3 dez. 2011.

MARTELETO, R.M. Redes sociais, mediação e apropriação de informações: situando campos, objetos e conceitos na pesquisa em Ciência da Informação. Pesquisa Brasileira em Ciência da Informação, Brasília, DF, v. 3, n. 1, p.27-46, jan./dez. 2010.

MELLO, E.D.; LUFT, V.C.; MEYER, F. Obesidade infantil: como podemos ser eficazes? Jornal de Pediatria, Rio de Janeiro, v. 80, n. 3, p. 173-182, 2004. Disponível em: $<$ http://dx.doi.org/10.2223/JPED.1180>.

ORGANIZAÇÃO MUNDIAL DE SAÚDE (OMS). Declaração de Alma-Ata, 1978.

ORGANIZAÇÃO MUNDIAL DE SAÚDE (OMS). Carta de Ottawa, 1986.

ORGANIZAÇÃO MUNDIAL DE SAÚDE (OMS). Declaração de Adelaide, 1988.

ORGANIZAÇÃO MUNDIAL DE SAÚDE (OMS). Declaração de Sundsvall, 1991.

ORGANIZAÇÃO MUNDIAL DE SAÚDE (OMS). Declaração de Jacarta, 1997.

ORGANIZAÇÃO MUNDIAL DE SAÚDE (OMS). Rede de Megapaíses, 1998.

ORGANIZAÇÃO MUNDIAL DE SAÚDE (OMS). Declaração do México, 2000.

ORGANIZAÇÃO PAN-AMERICANA DE SAÚDE (OPAS). Declaração de Santafé de Bogotá, 1992.

PIMENTEL, C. Blog, da internet à sala de aula. 2010. Tese (Doutorado em Educação) Universidade do Estado do Rio de Janeiro, Rio de Janeiro.

PRETTO, N.L.; SILVEIRA, S.A. (Org.). Além das redes de colaboração: internet, diversidade cultural e tecnologias do poder. Salvador: Edufba, 2008.

PRIMO, A. Conflito e cooperação em interações mediadas por computador. Contemporânea: Revista de Comunicação e Cultura, Salvador, v. 3, n. 1, p. 38-74, jun. 2005.

PRIMO, P. O aspecto relacional das interações na Web 2.0. In: CONGRESSO BRASILEIRO DE CIÊNCIAS DA COMUNICAÇÃO, 29., 2006, Brasília, DF. Anais... Brasília, DF: Sociedade Brasileira de Estudos Interdisciplinares da Comunicação, 2006.

RAHME, M.M.F. Laço social e educação: um estudo sobre os efeitos do encontro com o outro no contexto escolar. 2010. Tese (Doutorado em Educação) - Faculdade de Educação, Universidade de São Paulo, São Paulo. 
SANTAELLA, L. Da cultura das mídias à cibercultura: o advento do pós-humano. Revista Famecos, Porto Alegre, n. 22, p. 23-32, dez. 2003.

SANTAELLA, L. Navegar no ciberespaço: o perfil cognitivo do leitor imersivo. São Paulo: Paulus, 2004.

SANTANA, V.F. et. al. Redes sociais online: desafios e possibilidades para o contexto brasileiro. In: CONGRESSO DA SOCIEDADE BRASILEIRA DE COMPUTAÇÃO, 29., 2009, Bento Gonçalves. Anais... Bento Gonçalves: CSBC, 2009. p. 339-353. Disponível em: $<$ http://metropoa.inf.ufrgs.br/anais/pdf/semish/st04_04.pdf $>$. Acesso em: 21 jul. 2012.

SCHROCK, A. Examining social media usage: technology clusters and social network site membership. First Monday, Chicago, v. 14, n. 1, jan. 2009. Disponível em: $<$ http://frodo.lib.uic.edu/ojsjournals/index.php/fm/index>. Acesso em: 3 dez. 2011.

SODRÉ, M. Reinventando a cultura: a comunicação e seus produtos. São Paulo: Vozes, 2005.

STRAUBAHAAR, J.; LAROSE, R. Comunicação, mídia e tecnologia. São Paulo: Pioneira; Thomson Learning, 2004.

THEVENO, G. Blogging as a social media. Tourism and Hospitality Research, Birmingham, v. 7, n. 3/4, p. 282-289, 2007.

VYGOTSKY, L.S. A formação social da mente. São Paulo: Martins Fontes, 1989.

VYGOTSKY, L.S. Pensamento e linguagem. São Paulo: Martins Fontes, 1987.

Recebido em 23 de agosto de 2012.

Aprovado em 5 de abril de 2013. 